\title{
POTENTIAL EFFECTS OF OMEGA-3 FATTY ACIDS ON HIGH DENSITY LIPOPROTEIN CHOLESTEROL AND LOW DENSITY LIPOPROTEIN CHOLESTEROL IN MIDDLE AGED PATIENTS WITH DIABETES MELLITUS
}

\author{
HABIB TB ${ }^{1}$, AKHTER QS ${ }^{2}$, YEASMIN $\mathrm{N}^{3}$, IMAM $\mathrm{H}^{4}$, CHOWDHURY FUH ${ }^{5}$, HOSSAIN MZ ${ }^{6}$, \\ MIRDHA MS ${ }^{7}$, ISLAM MK ${ }^{8}$, RABBANI $\mathrm{SB}^{9}$, ALAM MM ${ }^{10}$
}

\begin{abstract}
Background: The one of the most common metabolic disorder that remains worldwide is Diabetes mellitus. Dietary intake of omega-3 fatty acid may confer a protective effect against diabetes, improves high density lipoprotein (HDL-C) and reduce low density lipoprotein cholesterol (LDL-C) levels.

Objective: To observe the effect of supplementation of omega-3 fatty acid on HDL and LDL levels in type 2 DM.

Methods: A prospective interventional study was conducted from January 2017 to December 2017. A total numbers of 52 diagnosed type 2 diabetic patients of both sexes were selected with age ranging from 40 to 50 years. Among them, 27 type 2 diabetic patients with supplementation of omega 3 fatty acid (2g/day) for 12 weeks was considered as study group. Another 25 type 2 diabetic patients without supplementation of omega 3 fatty acid were considered as control group for comparison. The study subjects were selected from Outpatient Department of Endocrinology, Dhaka Medical College Hospital, Dhaka and personal contact from Dhaka city on the basis of inclusion and exclusion criteria. The research work was carried out after obtaining ethical clearance from concerned departments, Research Review Committee and Ethical Review Committee of Dhaka medical college, Dhaka. The study parameters serum HDL was estimated by enzymatic colorimetric method in auto-analyzer and serum low density lipoprotein was calculated by using Friedwald formula in Department of Laboratory Medicine, Dhaka Medical College Hospital, Dhaka. The parameters were studied 2 times in study and control groups i.e. at the beginning of study (base line) and after 12 weeks of study period. Data were collected in pre-designed structured questionnaire from the researcher by herself. For statistical analysis, Paired Student's 't' test and Unpaired Student's 't' test were performed as applicable using SPSS for windows version 16.0.
\end{abstract}

Results: In this study High density lipoprotein cholesterol that is good cholesterol increased and low density lipoprotein cholesterol was decreased in diabetic patients after supplementation with omega-3 fatty acid in comparison to that of their baseline value. Again, after 12 weeks, high density lipoprotein was higher and low density lipoprotein cholesterol was lower in diabetic patients after supplementation with omega-3 fatty acid in comparison to control group.

Conclusion: After analyzing the results of the study, it can be concluded that omega-3 fatty acid can improve HDL and lowers $L D L$ levels in diabetic patients may be helpful to minimize the complications of type-2 diabetes mellitus.

Key words: Diabetes mellitus, glycemic status, lipid-profile, high density lipoprotein, Low density lipoprotein, Omega-3 fatty acid.

J Dhaka Med Coll. 2018; 27(2) : 190-194

1. Dr. Tamanna Binte Habib, Lecturer, Department of Physiology, Dhaka Medical College, Dhaka.

2. Dr. Qazi Shamima Akhter, Professor \& Head, Department of Physiology, Dhaka Medical College, Dhaka

3. Dr. Nahid Yeasmin, Assistant Professor, Department of Physiology, Dhaka Medical College, Dhaka.

4. Dr. Hasan Imam, Graded Specialist, Department of Anesthesia, Combined Military Hospital Bogra.

5. Dr. Forhad Uddin Hasan Chowdhury, Registrar, Department of Medicine, Dhaka Medical College Hospital.

6. Dr. Mohammad Zaid Hossain, Associate Professor of Medicine, Dhaka Medical College, Dhaka

7. Dr. Md. Sohel Mirdha, Medical Officer, NICVD, Dhaka

8. Dr. Md. Khademul Islam, Junior Consultant, Medicine, Goforgaon, Upazila Health Complex.

9. Dr. Safia Binte Rabbani, Specialist of Medicine, United Hospital, Dhaka

10. Dr. Md. Mahbubul Alam,Junior Consultant, Department ofMedicine, OSD, DGHS, Dept. of Haematology, DMCH,Dhaka Correspondence: Dr. Tamanna Binte Habib, Lecturer, Department of Physiology, Dhaka Medical College, Dhaka. E-mail: tamannapompy1234@gmail.com or hshimu109@gmail.com 


\section{Introduction}

Diabetes mellitus (DM) is a group of metabolic disease characterized by hyperglycemia resulting from defect in insulin secretion or insulin action or both. The chronic hyperglycemia of diabetes is associated with long term damage dysfunction and failure of various organs especially the eyes, kidneys, nerve, heart and blood vessel ${ }^{1}$. Diagnostic criteria of diabetes mellitus are fasting plasma glucose level e"7.0mmol/1 (126mg/dl) or plasma glucose 2 hours after an oral glucose e" 11.1 $\mathrm{mmol} / \mathrm{L}(200 \mathrm{mg} / \mathrm{dl})$ and HbA1ce" $6.5 \%{ }^{2}$.The prevalence of T2DM is expected to rise from 285 million in 2010 to 438 million by the year of $2030^{3}$. Within 2030, the prevalence of diabetes mellitus will be 11.1 million in Bangladesh 4 .

Insulin is the potent anabolic hormone which is essential for appropriate tissue development, growth and maintenance of whole body glucose homeostasis. Insulin regulates glucose homeostasis by increasing the rate of glucose uptake into striated muscle and adipose tissue. In the skeletal muscle, insulin prompts glucose uptake by stimulating translocation of GLUT-4 to plasma membrane ${ }^{5}$. Insulin resistance occurs when the insulin sensitive tissue loses response to insulin. The basic effect of insulin resistance on glucose metabolism is to prevent the uptake and utilization of glucose by most cells of the body. As a result blood glucose concentration increases, cell utilization of glucose falls, utilization of fat increases and free fatty acid level increases in blood ${ }^{6}$.

Omega-3 Fatty acids are a group of polyunsaturated fatty acids consists of alphalinolenic acid (ALA), eicosapentaenoic acid (EPA) and docosahexanoic acid (DHA). They are found in seafood including fatty fish (e.g. salmon, tuna and trout) and shellfish (e.g. crab, mussels and oysters).The omega 3 fatty acid; increases insulin sensitivity, helps in blood clotting, promote fat digestion, improve fertility, acts as a mood elevator and helps in brain development ${ }^{7}$.

Consumption of fish oil can decreases free fatty acid level, improve insulin sensitivity as well as reduce the incidence of type $2 \mathrm{DM}^{8}$. Poly unsaturated fatty acid act directly on insulin sensitive tissues, increases number of insulin receptors thus reducing insulin resistance ${ }^{9}$. Intake of diet rich in polyunsaturated fatty acid, particularly n-3 and n-6, facilitate the action of insulin through various metabolic pathways, which are suppression of hepatic lipogenesis, reduction of the release of triglycerols from liver, improvement in ketogenesis, and oxidation of fatty acids in liver 10. Moreover, intake of polyunsaturated fatty acid improve lipid metabolism and decreases triglyceride and total cholesterol level.

Omega- 3 fatty acid prevents this change by increasing peroxisome proliferator receptor gamma, increasing hepatic uptake and oxidation of free fatty acid in skeletal muscle ${ }^{11}$. Some author found significant reduction in serum total cholesterol and triglyceride ${ }^{12}$. Therefore the present study is intended to assess the effect of supplementation of omega3 fatty acid in Bangladeshi diabetic patient to improve the lipid profile.

\section{Methods}

This prospective, interventional study was done from Department of Physiology, Dhaka Medical College, Dhaka from January 2017 to December 2017. The research work was carried out after obtaining ethical clearance from concerned departments, Research Review Committee and Ethical Review Committee of Dhaka medical college, Dhaka. The patients were selected from outpatient department of Endocrinology, Dhaka medical college and personal contact from Dhaka city. At the Beginning of study 60 diagnosed type-2 diabetic patients were randomly selected on the basis of exclusion and inclusion criteria. There were 30 patients of control group and 30 patients of study groups recruited for completion of study, After 6 weeks of study period, 3 patients were dropped out from study group and 5 patients were dropped out from control group. Finally, total 52 type diabetic patient of both sexes with the age ranging from 40-50 years with FBG $7.0 \mathrm{mmol} /$ 1 or $126 \mathrm{mg} / \mathrm{dl}, \mathrm{HbA} 1 \mathrm{c} 6.5 \%$, serum total cholesterol $>200 \mathrm{mg} / \mathrm{dl}$, serum triglyceride $>150$ $\mathrm{mg} / \mathrm{dl}, \mathrm{LDL}>130 \mathrm{mg} / \mathrm{dl}, \mathrm{BMId} " 30 \mathrm{Kg} / \mathrm{m}^{2}$ and patients with oral hypoglycemic drug were included in this study. Subjects having history 
of heart, liver, endocrine disorder, insulin therapy, pregnant and lactating women were excluded from this study. For this study 27 diagnosed type-2 diabetic patients with omega3 fatty acid supplementation were selected as study group and 25 type-2 diabetic patients without oral omega-3 fatty supplementation were selected as control group. The study group again sub-divided into pre-supplementation group and after 12 weeks of supplementation as post supplementation group. The control group was sub-divided as pre and post followup group. After selection, the nature, purpose and benefits of the study were explained to each subject and informed written consent was taken from participants. Before taking blood detailed family and medical history were taken. Anthropometric measurement of the subjects was recorded and blood pressure was measured. All the information were recorded in a prefixed questionnaire. With aseptic precaution, $5 \mathrm{ml}$ of venous blood was collected from ante-cubital vein by a disposable plastic syringe from each subject after overnight fasting for biochemical tests. Serum high density lipoprotein cholesterol was estimated by enzymatic colorimetric method in auto-analyzer and low density lipoprotein was calculated by using Friedwald formula in department of Laboratory Medicine Dhaka Medical College Hospital, Dhaka. Omega-3 fatty acid (2gm) was supplied to study group then they were asked to intake twice daily for 12 weeks with proper instructions. Subjects were instructed not to change their diet and physical activities during the course of the study. A regular telephonic contact and periodic visit was made to participants because most of them are employee of Dhaka medical college. For statistical analysis, Paired Student's 't' test and Unpaired Student's ' $t$ ' test were performed as applicable using SPSS for windows version 16.0.Data were expressed as mean $\pm \mathrm{SE}$. The $p$ value of $<0.05$ was accepted as level of significance.

\section{Results}

In this study no significant difference were observed in age, sex, BMI, systolic and diastolic blood pressure between study and control group (Table 1).In this study, the mean serum high density lipoprotein cholesterol and low density lipoprotein cholesterol levels were almost similar and there is no statistical difference were observed at the beginning of the study. In study group, the mean serum high density lipoprotein $(p<.0 .001)$ was found higher and mean serum low density lipoprotein cholesterol $(p<.0001)$ level were found significantly lower in post supplementation group, than pre-supplementation group. Again the mean serum high density lipoprotein $(p<.0001)$ levels were found significantly higher and mean serum low density lipoprotein $(p<.0001)$ levels were found significantly lower and in study group compared to control group. In control group, there was no statistical difference were observed in mean serum HDL -C and LDL-C between pre-followup and post follow-up group.

\section{Table-I}

General characteristics of the patients in both groups $(N=52)$

Parameters

\begin{tabular}{|c|c|c|}
\hline & $\begin{array}{c}\text { Study group } \\
(\mathrm{n}=27)\end{array}$ & $\begin{array}{c}\text { Control group } \\
(\mathrm{n}=25)\end{array}$ \\
\hline Age (years) ${ }^{a}$ & $45.90 \pm 3.80^{\mathrm{ns}}$ & $44.92 \pm 3.75$ \\
\hline \multicolumn{3}{|l|}{$\operatorname{Sex}(\%)^{b}$} \\
\hline Male & $18(66.7 \%)^{\mathrm{ns}}$ & $11(44 \%)$ \\
\hline Female & $9(33.3 \%) \mathrm{ns}$ & $14(56 \%)$ \\
\hline BMI $\left(\mathrm{kg} / \mathrm{m}^{2}\right)^{\mathrm{a}}$ & $25.03 \pm 2.27 \mathrm{~ns}$ & $25.87 \pm 1.75$ \\
\hline $\begin{array}{l}\text { Systolic BPa } \\
\text { (mmHg) }\end{array}$ & $119.07 \pm 7.08^{\mathrm{ns}}$ & $121.79 \pm 4.47$ \\
\hline $\begin{array}{l}\text { Diastolic } \mathrm{BP}^{\mathrm{a}} \\
(\mathrm{mmHg})\end{array}$ & $79.63 \pm 6.26^{\mathrm{ns}}$ & $80.00 \pm 0.00$ \\
\hline $\begin{array}{l}\text { Duration of } \\
\text { disease }^{\mathrm{a}} \text { (years) }\end{array}$ & $5.43 \pm 1.50 \mathrm{~ns}$ & $5.35 \pm 1.57$ \\
\hline
\end{tabular}

Results were expressed as mean \pm SD. $a=$ Unpaired Student's ' $t$ ' test was performed to compare between the groups. $b=$ Chi Square test was performed to compare male and female between the groups. The test of significance was calculated and $p$ value $<0.05$ was accepted as level of significance. $\mathrm{N}=$ total number of subjects, $\mathrm{n}=$ number of subjects in each group $\mathrm{ns}=$ non-significant $* / * * / * * *$ significant. T2DMS=Type 2 diabetes mellitus with supplementation T2DM=Type 2 diabetes mellitus without supplementation 
Table II

Serum total cholesterol and serum triglyceride levels in different groups $(N=52)$

\begin{tabular}{lcccc}
\hline Parameters & \multicolumn{2}{c}{ Study group $(\mathrm{n}=27)$} & \multicolumn{2}{c}{ Control group $(\mathrm{n}=25)$} \\
& Pre-supplemenation & Post supplementation & Pre-follow-up & Post follow-up \\
& group & group & group & group \\
\hline HDL $(\mathrm{mg} / \mathrm{dl})$ & $29.95 \pm 7.34$ & $38.48 \pm 3.67^{* *}$ & $29.20 \pm 4.20$ & $29.96 \pm 4.43^{\# \#}$ \\
LDL $(\mathrm{mg} / \mathrm{dl})$ & $157.41 \pm 40.00$ & $128.75 \pm 18.02^{*}$ & $157.68 \pm 14.68$ & $156.88 \pm 15.20^{\# \#}$ \\
\hline
\end{tabular}

Results are expressed a $\mathrm{s}$ mean $\pm \mathrm{SD}$. a = Paired student's $\mathrm{t}$ test was performed for comparison within groups and $b=$ unpaired $t$ test was performed to compare between groups. $p$ value $<0.05$ was accepted as level of significance. $\mathrm{N}=$ total number of subjects, $\mathrm{n}=$ number of subjects in each group, $\mathrm{HDL}=$ High density lipoprotein, $\mathrm{LDL}=$ triglyceride $\quad{ }^{*}=$ study group baseline vs study group after 12 weeks of supplementation; \# = study group after 12 weeks vs control group after 12 weeks); $\left({ }^{*} p<.01,{ }^{* *} p<.001\right.$; $p<.01$, \#\# $\left.p<.001\right)$.

\section{Discussion}

In the present study, the mean serum high density lipoprotein was significantly higher and low density lipoprotein levels were lower in patients of T2DM after supplementation with omega-3 fatty acid in comparison to that of their baseline value. Again, after 12 weeks, mean high density lipoprotein (.001) level was significantly higher in type-2 diabetic patients supplemented with omega-3 fatty acid in comparison to that of diabetic control group without omega-3 fatty acid. N-3 fatty acids are considered as well tolerated drug in treatment of cardiovascular risk factors. The Poly unsaturated fatty acid increases Scavenger Receptor Class B Type-1 receptor (SR-B1) which helps in increasing plasma HDL level by increasing expression of main hepatic genes which helps in reverse cholesterol transport ${ }^{13}$. Almost similar type of result were observed by different researchers of different countries ${ }^{14,15,16,17}$. On the contrary, found no significant difference in lipid profile in patients after supplementation of omega-3 fatty acid in comparison to that of their baseline values and diabetic control group who were not supplemented with omega-3 fatty acid. There were a history of less physical activity in the study subjects that might be contributed the result of those study. Literature review suggested that, Omega-3 fatty acid has a role on reducing serum low density lipoprotein level. Diet rich in polyunsaturated fatty acid decreases LDL to binding with its receptor as a result in change of membrane fluidity. Thus, omega-3 fatty acid reduces serum low density lipoprotein level that facilitates the binding of insulin to its receptor and improves insulin sensitivity 18 .

In the present study serum-high density lipoprotein level rises and serum low density lipoprotein levels decreases in patients with T2DM after supplementation of omega-3 fatty acid in comparison to their baseline value and control group. Omega-3 fatty acid supplementation increases serum HDL level and it also decreases LDL by altering membrane fluidity. This facilates the binding of insulin to its receptor and improves insulin sensitivity.

\section{Conclusions}

After analyzing the results of the study, it can be concluded that supplementation of omega-3 fatty acid can improve serum HDL-C and serum LDL-C levels in patients with type- 2 diabetes mellitus. Therefore, omega- 3 fatty acid containing food may be helpful to minimize the complications in type- 2 diabetes mellitus.

\section{Conflict of Interest: None}

\section{Acknowledgement}

The authors are thankful to the study subjects for their active, sincere and voluntary participation.

\section{References}

1. American Diabetes Association. Diagnostic and classification of diabetes mellitus. Diabetes Care 2017; 40(1):S11-S24

2. World Health Organization. Definition and diagnosis of diabetes mellitus and intermediate hyperglycemia: 
Report of a WHO/IDF. Consultation. [Internet].Geneva: World Health Organization;2011. [Cited 2017 May 18].Available from ;https;// www.idf.org.

3. Ramachandran A, Snehalata C, Shetty S, Nandita A.Trends in prevalence of diabetes in Asian countries. World J of Diabetes 2012; 3(6):110-117.

4. Baynest HW. Classification, pathophysiology, diagnosis and management of diabetes mellitus. J of Diabetes Metab 2015; 6(541):1-13.

5. Pessin JF and Saltiel S.Signaling pathways in insulin action: molecular targets of insulin. The $\mathrm{J}$ of Clin inv 2000;106(2) : 155-169.

6. Delarue $\mathrm{J}$ and Magnan C. Free acids and insulin resistance. Research Gate 2014 ;10(1): 142-148.

7. National Center for Complementary and Integrative Health n.d., Omega-3 supplements in depth. [Interenet] 2017[Cited on April 23]2017. Available from:

http://nccih.nih.gov//omega-3 supplements in depth/html

8. Albert BB, Derraik JGB, Brenan CM, Smith GC, Glarg ML, Smith DC, Hofman PL and Cutfield WS, 'Higher omega-3 index is associated with increased insulin sensitivity and more favourable metabolic profile in middle-aged overweight men'.Sci Rep 2014;4(6696):1-8.

9. Laila $\mathrm{AZ}$ and Lanza IR.Insulin -Sensitizing effects of omega-3 fatty acids: lost in translation. Nutr 2016;8 (329) :1-24.

10. Lopez AL, Ramos RV, Carrillo BE. Type 2 Diabetes, PUFAs and vitamin D: their relation to inflammation. $\mathrm{J}$ of Immun Res 2014; 1:1-14.
11. Flachs P, Rossmeisl M, Kopecky J. The effect of n-3 Fatty Acids on Glucose Homeostasis and Insulin Sensitivity. Phy Res 2013; 63(1): 93-98.

12. Ellulu MS, Khazai H, Patimah I, Rahmat A .Effect of long chain omega-3 polyunsaturated fatty acids on inflammation and metabolic markers in hypertensive and/or diabetic obese adults: a randomized control trial. Food \& Nut Res 2017;60(1) :1-9.

13. Pizzini A, Lunger L, Demetz E and Hilbe R.The Role of Omega-3 Fatty Acids in Reverse Cholesterol Transport.Nutrients 2017;9(10): 1-12.

14. Zambon S, Friday KE, Childs MT, Fujimoto WY, Bierman EL and Ensinck JW.Effect of glyburide and ù3 fatty acid dietary supplements on glucose and lipid metabolism in patients with non-insulindependent diabetes mellitus. Am J of Clin Nutr 1992;56(1):447-454.

15. Thota RN, Acharya SH, Abbott KA et al. Curcumin and long chain omega-3 polyunsaturated fatty acids for prevention of type-2 diabetes. Trials 2016; 17(565):1-11.

16. Mahmoodi MR, Kimiagar M, Mehrabi Y.The effect of omega-3 plus vitamin $\mathrm{E}$ and zinc plus vitamin $\mathrm{C}$ supplementation on cardiovascular risk markers in postmenopausal women with type- 2 diabetes. Thera Adv Endocrinol Metab 2014; 5(4): 67-76.

17. Shidfar F, Keshavaraz A, Hosseyni S, Ameri A. Effect of omega -3 fatty acid supplements on serum lipids, apo-lipopotein and malondehyde in type 2 diabetes patient. East Mediterranean Health J 2008;14(2):305-312.

18. Fernandez ML and West KL. Mechanism by which Dietary Fatty Acids Modulate Plasma Lipids. J Nutr 2005;135:2075-2078. 